\title{
Temperature's Effect on Color Change and Mechanical Properties of Poplar Powder Compact Formed by Warm Compaction
}

\author{
Liqiang Zhang,* Zhizhong Long, Zhili Tan, and Qingding Wu
}

Warm compaction technology is an eco-friendly method to improve the added value of poplar. In this work, the wood powder was compacted in the mold between $120^{\circ} \mathrm{C}$ to $200{ }^{\circ} \mathrm{C}$, at $80 \mathrm{MPa}$ for $30 \mathrm{~min}$. The color change, chemical properties, and mechanical properties were evaluated. The color of the formed compaction darkened uniformly. The CIE lightness color coordinate $\left(L^{*}\right)$ and chroma coordinates $a^{*}$ and $b^{*}$ decreased with the increase of forming temperature. Fourier infrared spectral analysis showed degradation of carbohydrates, along with the formation of a new chemical structure of darker color. Mechanical properties including modulus of rupture (MOR) and modulus of elasticity (MOE) of compacted wood increased initially and then decreased. These results provide a reference for the surface color control of thermally forming materials.

Keywords: Poplar powder; Warm compaction; Surface color; Mechanical properties

Contact information: College of Mechanical and Electrical Engineering, Central South University of Forestry and Technology, Changsha 410004, P. R. China; *Corresponding author: 21384881@qq.com

\section{INTRODUCTION}

Multi-value utilization of wood residues has extensively been studied for relieving dependence on native wood (Altunok et al. 2015). Through the warm-press forming technology, wood powder can be formed as a new material with high density and high added value.

During the forming process, the molecular adhesive chemical components, such as lignin, start to diffuse and then reconnect to form an isotropic wood material. No additives, such as lubricants or adhesives, are added in the forming process. No harmful substances are released during use. The temperature in the warm-press process has considerable influence on the characteristics of the compacts, such as surface color, chemical composition, and mechanical properties. There has been a lack of studies presenting the change of characteristics for warm-pressed compacts.

In this paper, an international standard colorimetric system using the CIE $L * a * b *$ method was applied to measure the change of surface color for the warm-pressed compacts. The chemical changes were evaluated using Fourier transform infrared (FTIR) spectrometry.

The change in density and the static mechanical properties of warm-pressed compacts were also evaluated. The correlations between the forming temperature and the characteristics were studied. 


\section{EXPERIMENTAL}

\section{Materials}

Specimen preparation

Fast-growing poplar was the object of research. After natural air-drying, the specimens were pulverized using a F160 test grinder (Zhongxing Weiye Instrument Manufacturing Co., Ltd., Beijing, China). The initial moisture content of poplar flour was $8.56 \%$. Poplar powder passing through an 80-mesh screen was obtained by a vibrating screener. The $80 \mathrm{~g}$ powder was uniformly spread into the mold of an HX100 compression machine (Institute of Thermal Processing Engineering, Huazhong University of Science and Technology, Wuhan, China). The forming pressure and the holding time used was 80 $\mathrm{MPa}$ and $30 \mathrm{~min}$, respectively. The dimension (length $\times$ width $\times$ thickness) of the blank is $128 \mathrm{~mm} \times 35 \mathrm{~mm} \times 10 \mathrm{~mm}$. The forming temperatures studied were set to $120{ }^{\circ} \mathrm{C}, 140{ }^{\circ} \mathrm{C}$, $160{ }^{\circ} \mathrm{C}, 180{ }^{\circ} \mathrm{C}$, and $200{ }^{\circ} \mathrm{C}$. The mold was heated from room temperature to the experimental temperature at the speed of $2{ }^{\circ} \mathrm{C} / \mathrm{min}$. Figure 1 shows the flow chart of the warm-press forming. A specimen formed at the temperature $100{ }^{\circ} \mathrm{C}$, at $30 \mathrm{MPa}$ pressure, and the holding time of 10 min was used as a control group. The forming conditions of each experiment are shown in Table 1.

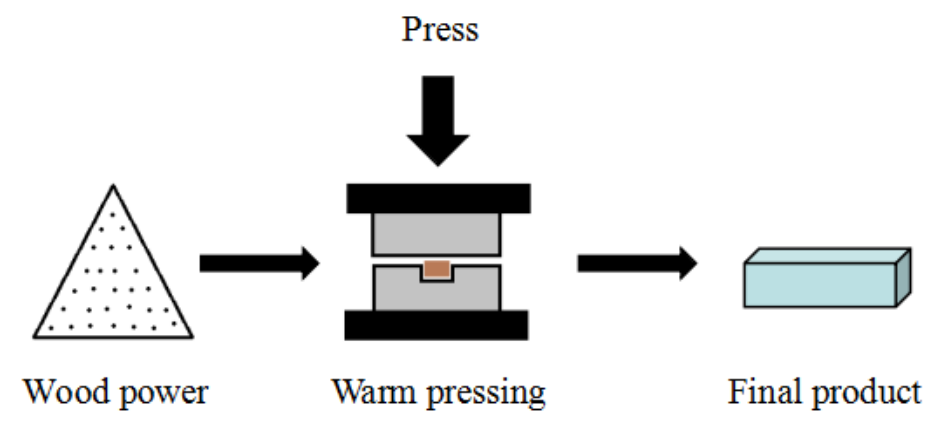

Fig. 1. Flow chart of warm pressing

Table 1. Forming Condition of Tested Specimens

\begin{tabular}{|c|c|c|c|}
\hline Category & Temperature $\left({ }^{\circ} \mathrm{C}\right)$ & Pressure $(\mathrm{MPa})$ & Holding Time $(\mathrm{min})$ \\
\hline Control group & 100 & 30 & 10 \\
\hline Experimental group & 120 to 200 & 80 & 30 \\
\hline
\end{tabular}

\section{Methods}

Measurement of color changes

Color changes were measured with a printer using the CIE Lab method. CIE Lab parameters $L^{*}, a^{*}$, and $b^{*}$ were measured. The $L^{*}$ represents lightness $(L=0$ for total black, $L=100$ for pure white); $a^{*}$ represents the red-green index ( $+a$ for redness, $-a$ for green); and $b^{*}$ is the yellow-blue index ( $b$ for yellow, $-b$ for blue). The specimens were scanned by the printer (MP752; Ricoh, Tokyo, Japan). Then, the values for $L^{*}, a^{*}, b^{*}$ of the specimens were obtained by Photoshop software (Adobe Systems, Photoshop CC 2015, San Jose, CA, USA). The total color change $\Delta E^{*}$ was calculated using Eq. 1,

$$
\Delta E^{*}=\sqrt{\left(\Delta L^{*}\right)^{2}+\left(\Delta a^{*}\right)^{2}+\left(\Delta b^{*}\right)^{2}}
$$


where $\Delta L^{*}, \Delta a^{*}$, and $\Delta b^{*}$ are the color changes between the control group and the experimental result. The average value is calculated according to the values measured at five different positions randomly selected on the blank surface.

\section{FTIR characterization of specimen}

The FTIR spectra of specimens were measured using a Thermo Scientific Nicolet iS10 device (Thermo Fisher Nicolet, Waltham, MA, USA). Spectra were measured directly from the surface of specimens via attenuated total reflectance (ATR) technique at a spectral resolution of $4 \mathrm{~cm}^{-1}$ with 32 scans within the scanning range of $400 \mathrm{~cm}^{-1}$ to $4000 \mathrm{~cm}^{-1}$.

\section{Evaluation of static mechanical properties}

The static mechanical properties including static bending strength and modulus of elasticity of specimens were measured using a $10 \mathrm{kN}$ universal testing machine (WDW100; Jinan Kairui Testing Machine Co., Ltd., Jinan, China) with a three-point flexure. The span used was $80 \mathrm{~mm}$, and the tests were performed under displacement control at a crosshead speed of $2 \mathrm{~mm} / \mathrm{min}$. Data were captured digitally. Then, static bending strength and modulus of elasticity of the specimens were calculated automatically using Trapezium 2 software (Jinan Blue Wave Test Equipment Co., Ltd., v.10.3, Jinan, China). The mean value was calculated by five replicates in each case. The density was calculated with Eq. 2 , as follows,

$$
\rho=m / V
$$

where $\rho$ is the density, $m$ is the mass after the compact is formed, and $V$ is the volume after the compact is formed.

\section{RESULTS AND DISCUSSION}

\section{Change in Density}

Figure 2 shows that the density of specimens changed with forming temperature during warm compaction.

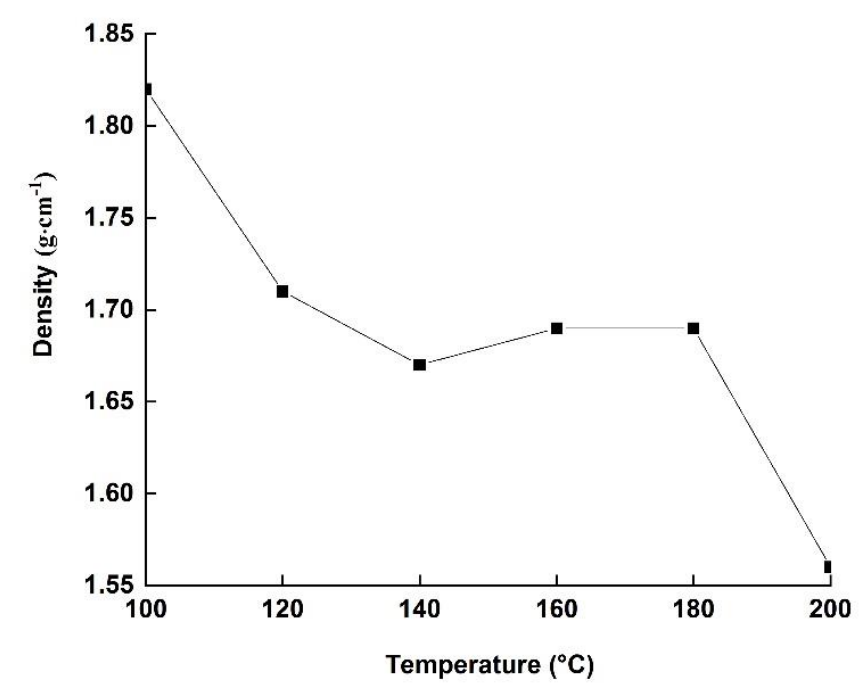

Fig. 2. Density variation of specimens at different forming temperature 
It can be seen from Fig. 2 that the density was the largest when the forming temperature of the control group was $100{ }^{\circ} \mathrm{C}$. When the temperature was less than $180^{\circ} \mathrm{C}$ it had a minimal effect on the density of the compact specimen. The density decreased with increasing temperature above $180{ }^{\circ} \mathrm{C}$ and decreased rapidly down to a minimum value of approximately 1.5 at $200{ }^{\circ} \mathrm{C}$. The compacted wood blocks almost completely turned black at $200{ }^{\circ} \mathrm{C}$. The decrease of density may have been attributed to the internal water evaporating more completely during the carbonization process.

\section{Water Content Change in Specimens}

Table 2 shows the water content of the powder in the control group and the blank sample. The water content of the pressing sample powder decreased with the increase of forming temperature. When the forming temperature was $200^{\circ} \mathrm{C}$, the water content of the billet sample reached a minimum of $2.73 \%$. There was no significant difference in moisture content within the range 140 to $180{ }^{\circ} \mathrm{C}$. The results of moisture content test were similar to those of density test.

Table 2. Water Content of Tested Specimens

\begin{tabular}{|c|c|c|c|c|c|c|}
\hline Tempercature & Control group & $120{ }^{\circ} \mathrm{C}$ & $140{ }^{\circ} \mathrm{C}$ & $160{ }^{\circ} \mathrm{C}$ & $180{ }^{\circ} \mathrm{C}$ & $200{ }^{\circ} \mathrm{C}$ \\
\hline water content & $9.32 \%$ & $5.21 \%$ & $4.64 \%$ & $4.42 \%$ & $4.10 \%$ & $2.73 \%$ \\
\hline
\end{tabular}

\section{Color Change in Specimen}

The specimen became darker upon warm compaction and displayed uniform color throughout, as shown in Fig. 3. Figure 3 shows the change of the poplar powder compact at various forming temperatures. The surface color changed noticeably and continuously deepened with the increase of temperature. The color varied from light apricot to light brown, to brown, and finally carbonized to black.

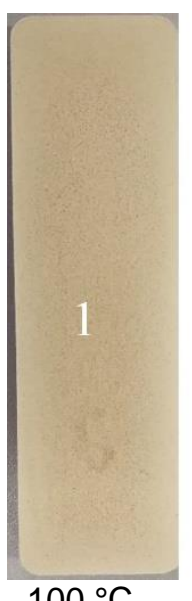

$100{ }^{\circ} \mathrm{C}$

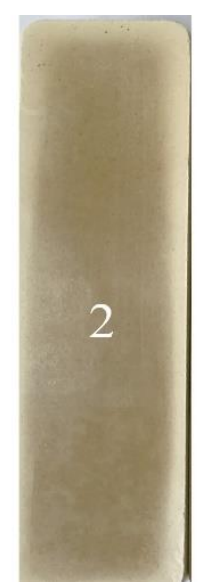

$120^{\circ} \mathrm{C}$

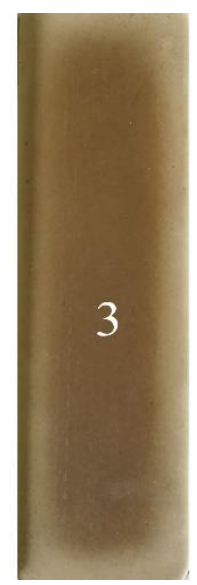

$140^{\circ} \mathrm{C}$

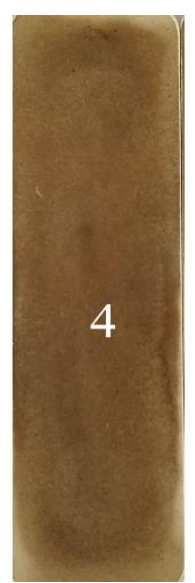

$160^{\circ} \mathrm{C}$

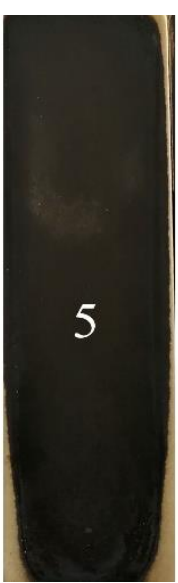

$180^{\circ} \mathrm{C}$

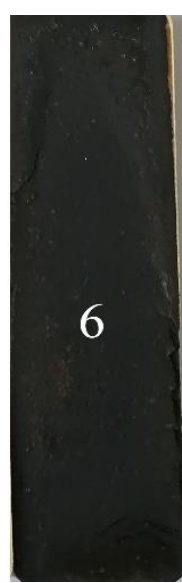

$200^{\circ} \mathrm{C}$

Fig. 3. Surface color of test specimens at different forming temperature

The effect of the forming temperature on the color parameters $L^{*}, a^{*}$, and $b^{*}$ is shown in Fig. 4. In general, the color parameters of the poplar powder compact decreased 
with the increase of forming temperature. The lightness value $L^{*}$ decreased from 46.4 to 15.4 with the increase of temperature from $120^{\circ} \mathrm{C}$ to $200{ }^{\circ} \mathrm{C}$. The change trend was in agreement with the color change of poplar powder compact discussed above. The decrease of color parameters $L^{*}, a^{*}$, and $b^{*}$ with increasing temperature may be due to the change of chemical composition during warm pressing (Chai et al. 2016).

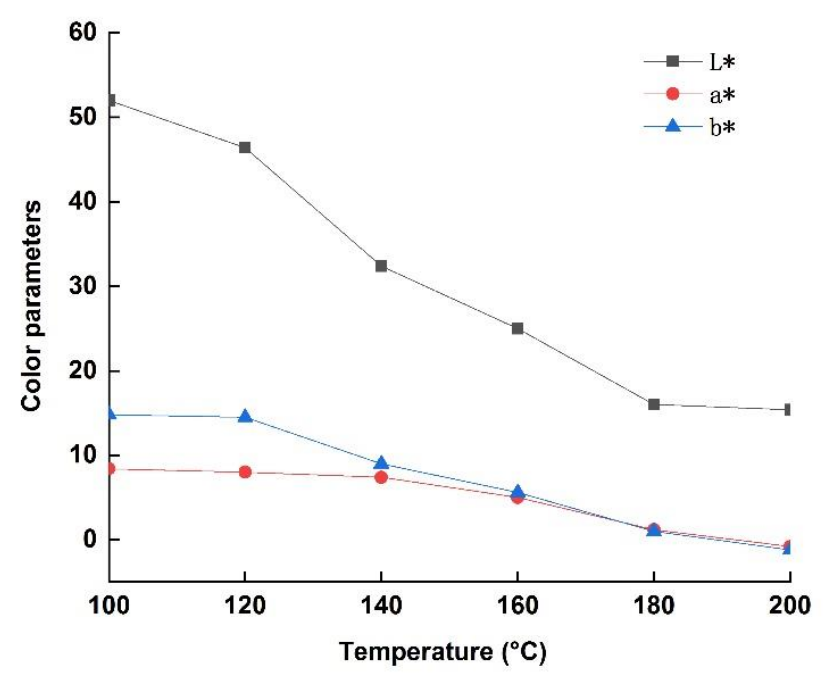

Fig. 4. Change of color parameters at different forming temperature

The change of overall color difference $\Delta E^{*}$ with temperature is shown in Fig. 5. The color gradually darkened between 120 to $180^{\circ} \mathrm{C}$. The color change rate changes fastest within the range 120 to $140{ }^{\circ} \mathrm{C}$. The overall color difference $\Delta E^{*}$ gradually increased from 28.5 to 60.3 with the temperature. The value $\Delta E^{*}$ increased gradually at temperature less than $180^{\circ} \mathrm{C}$ and changed only slightly above $180{ }^{\circ} \mathrm{C}$.

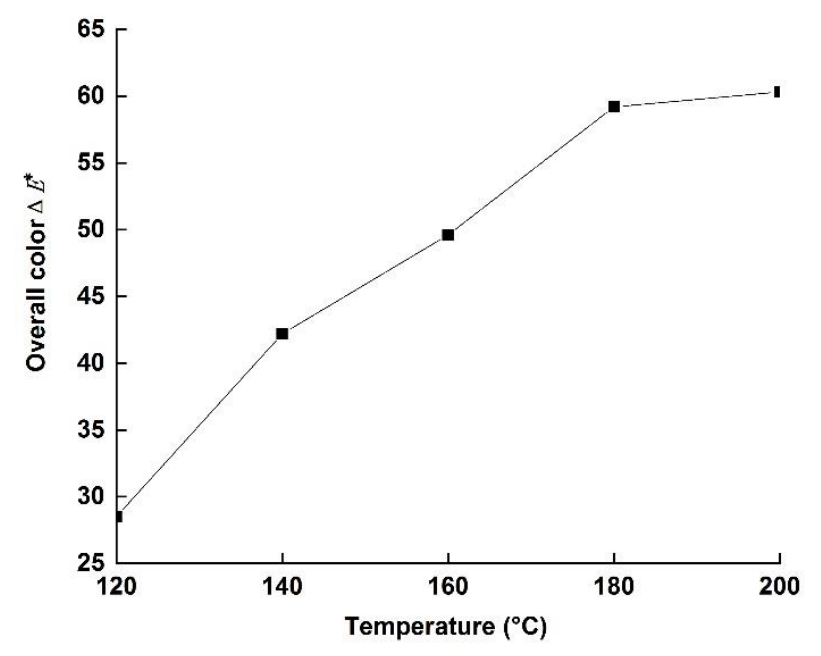

Fig. 5. Overall color difference of test specimen at different forming temperature 


\section{Chemical Changes in the Poplar Powder Compact}

A variety of chemical compositional changes occurred during the warm-pressing process for poplar powder. The main components of wood include lignin, hemicellulose, cellulose, and extractives. Compared to other polymer materials, the hemicellulose is more sensitive to temperature. As the forming temperature increased, the hemicellulose began to undergo a deacetylation reaction and released acetic acid. This accelerated the deacetylation reaction (Yang et al. 2015; Zheng et al. 2016). More sensitivities to thermal degradation were indicated by the substantial change in hemicellulose content. Compared to the hemicellulose, the cellulose is less affected by the temperature due to its unique semicrystalline nature. The increase in temperature eventually led to an increase in the proportion of lignin content, which could be attributed to the relative reduction of carbohydrate contents and the formation of fake lignin after dehydration and condensation of hemicellulose (Boonstra et al. 2006; Srinivas and Pandey 2012).

The specimens with obvious color change at $120^{\circ} \mathrm{C}, 160{ }^{\circ} \mathrm{C}$, and $180{ }^{\circ} \mathrm{C}$ in Fig. 3 were analyzed by FTIR spectra. Figure 6 shows the FTIR spectra of pure poplar powder and compacted poplar powder at $800 \mathrm{~cm}^{-1}$ to $4000 \mathrm{~cm}^{-1}$ segment. The change in the IR peak value can reflect the effect of temperature on chemical composition of poplar powder compact. It can be seen from Fig. 6 that the absorption peak of formed and unformed poplar powder shifted and changed at $3360 \mathrm{~cm}^{-1}, 1737 \mathrm{~cm}^{-1}, 1463 \mathrm{~cm}^{-1}, 1430 \mathrm{~cm}^{-1}, 1161 \mathrm{~cm}^{-1}$, and $1120 \mathrm{~cm}^{-1}$.

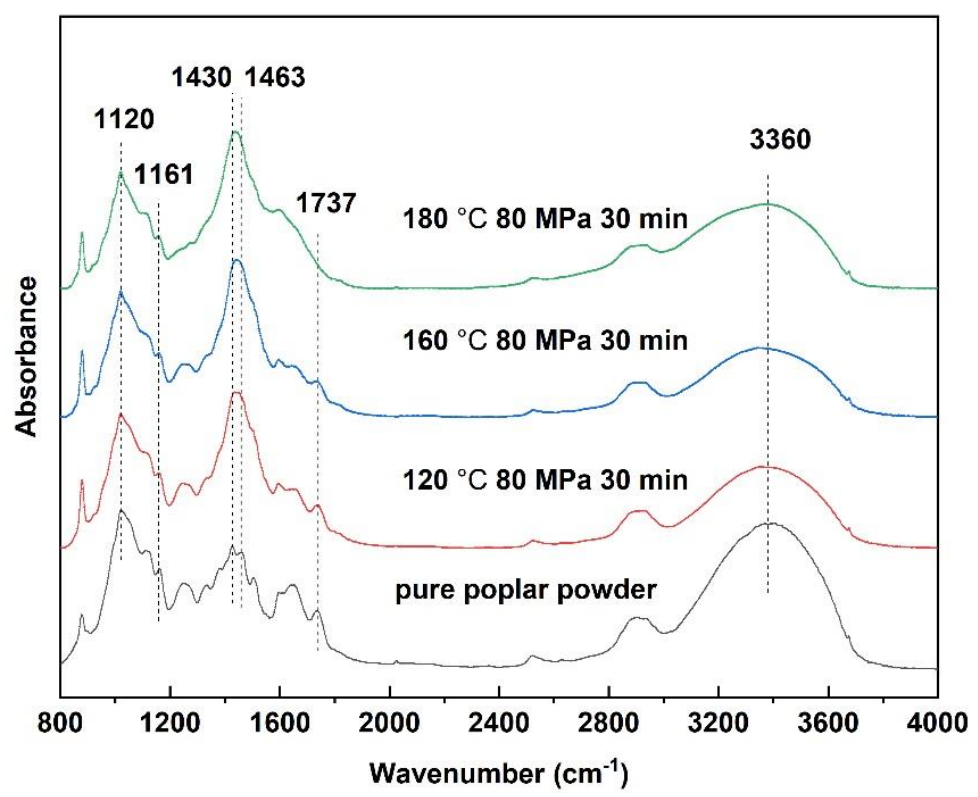

Fig. 6. Infrared spectra of pure and formed poplar powder

The absorption peak belonging to the hydroxyl group (-OH) was clearly decreased at $3360 \mathrm{~cm}^{-1}$ after warm compaction. The absorption peak at $1737 \mathrm{~cm}^{-1}$ was attributed to nonconjugated carbonyl group $(\mathrm{C}=\mathrm{O})$. As the forming temperature increased, the intensity of the absorption peak was visibly weakened, which may be due to the deacetylation of hemicellulose (Sun et al. 2017). The absorbance of band at $1161 \mathrm{~cm}^{-1}$ and $1120 \mathrm{~cm}^{-1}$ for C-O-C stretch in hemicellulose and cellulose, respectively, decreased slightly with the increase of temperature and thus indicated its degradation. The absorption peaks at 1463 $\mathrm{cm}^{-1}$ and $1430 \mathrm{~cm}^{-1}$ were respectively attributed to methyl $\mathrm{C}-\mathrm{H}$ bending vibration and 
benzene ring skeleton structure combined with $\mathrm{C}-\mathrm{H}$ bond vibration. A notable change occurred from double peaks to shoulder peaks. The absorbance was the highest with the increasing temperature, and reached the highest value at $180^{\circ} \mathrm{C}$. This may result from the softening and plasticization of the lignin. Breakage of the benzene ring side chain caused the relative increase of benzene ring skeleton (Li et al. 2015; Shangguan et al. 2016). The pyrolysis of hemicellulose and cellulose, as well as the pyrolysis, condensation, and oxidation of lignin have generated new chromogenic substances in some studies. This results in deepening of the surface color of wood (Chen et al. 2012; Wang et al. 2019).

\section{Mechanical Properties in Warm Compaction}

Figures 7 and 8 show the variation of mechanical properties with temperature for the compaction.

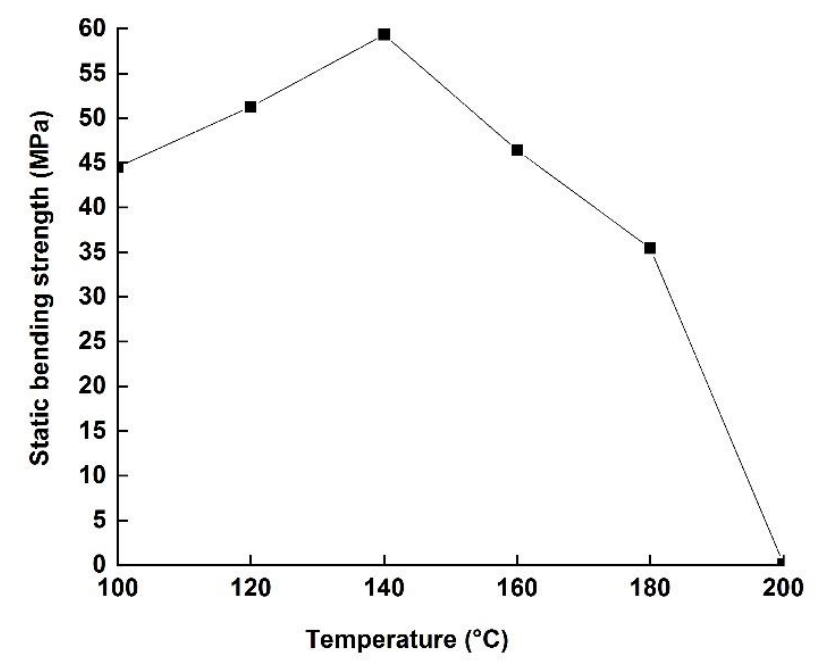

Fig. 7. MOR change of the specimens with temperature

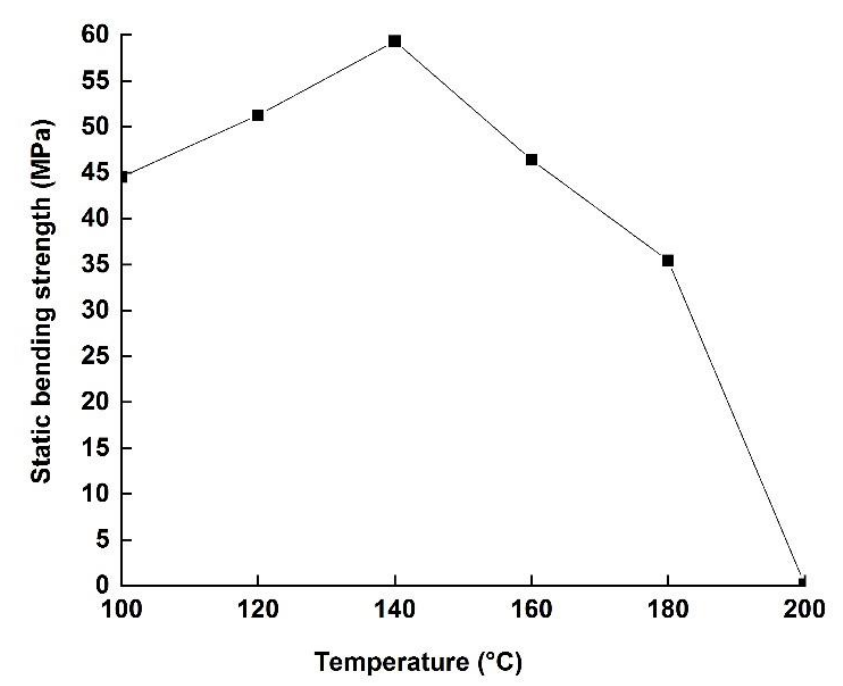

Fig. 8. MOE change of the specimens with temperature 
It can be clearly seen that the temperature had a great influence on the static bending strength and modulus of elasticity of compaction. With the increasing temperature, the static bending strength and modulus of elasticity initially increased and then decreased. Strength reached a maximum value at $140{ }^{\circ} \mathrm{C}$ and then decreased down to a minimum value at $200{ }^{\circ} \mathrm{C}$. The change in the static bending strength may be due to the enhancement of the molecules' activity under the proper temperature. More active molecules induce stronger bonding between the fibers, thus facilitating the bonding between the fibers. The reason for the strength decline after $140{ }^{\circ} \mathrm{C}$ may be the mechanical strength reduction caused by the destruction of hemicellulose chain. Nevertheless, the fibers were eventually carbonized and the strength was reduced at higher temperature (Wang et al. 2016).

\section{CONCLUSIONS}

1. The surface color of compaction was uniform throughout the tested specimens. CIE lightness color coordinate $L^{*}$, chroma coordinate $a^{*}$, and chroma coordinate $b^{*}$ decreased with forming temperature. The results show that $L^{*}, a^{*}, b^{*}$ reached a maximum value at $120{ }^{\circ} \mathrm{C}$ and decreased to a minimum value at $200{ }^{\circ} \mathrm{C}$. The color coefficient of the specimen decreased most rapidly at 160 to $180{ }^{\circ} \mathrm{C}$.

2. The FTIR analysis revealed the degradation of carbohydrate, resulting in generation of a new structure that was responsible for darker color. When the shaping temperature was lower than $200{ }^{\circ} \mathrm{C}$, the hemicellulose content changed more obviously than that of cellulose and lignin. The increase of phenyl in the test piece makes the surface color of the test piece tend to be black, while the decrease of quinones and phenols makes the surface color tend to be green and blue, resulting in the deepening of the surface color of the test piece.

3. The mechanical properties can be improved by hot pressing technology when the warm pressing temperature is increased to $140{ }^{\circ} \mathrm{C}$. When the temperature rises to $200{ }^{\circ} \mathrm{C}$, the mechanical properties of the compacting sample were greatly decreased.

\section{ACKNOWLEDGEMENTS}

This work was supported by funding from the Scientific Research Project of Hunan Provincial Department of Education (No. 19A512), the Natural Science Foundation of Hunan Province (No. 2018JJ2681), and the Scientific Innovation Fund for Post-graduates of Hunan Provincial (No. CX20190628).

\section{REFERENCES CITED}

Altunok, M., Kureli, I., and Pulat, M. (2015). "Determination of some physical and mechanical properties of the wood-based panels modified by acrylic textile fiber," Materials Sciences and Applications 6(6), 519-526. DOI: 10.4236/msa.2015.66055

Boonstra, M. J., and Tjeerdsma, B. (2006). "Chemical analysis of heat-treated softwoods," Holz als Roh- und Werkstoff 64, 204-211. DOI: 10.1007/s00107-0050078-4 
Chai, Y. B., Liu, J. L., Wang, Z., and Zhao, Y. (2016). "Dimensional stability and mechanical properties of plantation poplar wood esterified using acetic anhydride," BioResources 12(1), 912-922. DOI: 10.15376/biores.12.1.912-922

Chen, Y., Fan, Y. M., Gao, J. M., and Stark, N. M. (2012). "The effect of heat treatment on the chemical and color change of black locust (Robinia pseudoacacia) wood flour," BioResources 7(1), 1157-1170. DOI: 10.15376/biores.7.1.1157-1170

Li, M. Y., Cheng, S. C., Li, D., Wang, S. N., Huang, A. M., and Sun, S. Q. (2015). "Structural characterization of steam-heat treated Tectona grandis wood analyzed by FT-IR and 2D-IR correlation spectroscopy," Chinese Chemical Letters 26(2), 221225. DOI: $10.1016 /$ j.cclet.2014.11.024

Shangguan, W. W., Gong, Y. C., Zhao, R. J., and Ren, H. Q. (2016). "Effects of heat treatment on the properties of bamboo scrimber," Journal of Wood Science 62(5), 383-391. DOI: 10.1007/s10086-016-1574-3

Srinivas, K., and Pandey, K. (2012). "Effect of heat treatment on color changes, dimensional stability, and mechanical properties of wood," Journal of Wood Chemistry and Technology 32(4), 304-316. DOI: 10.1080/02773813.2012.674170

Sun, B. L., Wang, Z., and Liu, J. L. (2017). "Changes of chemical properties and the water vapour sorption of Eucalyptus pellita wood thermally modified in vacuum," Journal of Wood Science 63, 133-139. DOI: 10.1007/s10086-016-1601-4

Wang, X. D., Hou, Q. X., Zhang, X., Zhang, Y. C., Liu, W., Xu, C. L., and Zhang, F. D. (2019). "Color evolution of poplar wood chips and its response to lignin and extractives changes in autohydrolysis pretreatment," International Journal of Biological Macromolecules (In Press). DOI: 10.1016/j.ijbiomac.2019.11.224

Wang, Z., Sun, B. L., and Liu, J. L. (2016). "Effect of thermo-vacuum treatment on the color and chemistry of larch wood," BioResources 11(1), 2349-2360. DOI: 10.15376/biores.11.1.2349-2360

Yang, Y., Zhan, T. Y., Lv, J. X., and Jiang, J. H. (2015). "Influences of thermo-vacuum treatment on colors and chemical compositions of alder birch wood," BioResources 10(4), 7936-7945. DOI: 10.15376/biores.10.4.7936-7945

Zheng, A. Q., Jiang, L. Q., Zhao, Z. L., Chang, S., Huang, Z., Zhao, K., He, F., and Li, H. B. (2016). "Effect of hydrothermal treatment on chemical structure and pyrolysis behavior of eucalyptus wood," Energy \& Fuels 30(4), 3057-3065. DOI: 10.1021/acs.energyfuels.5b03005

Article submitted: May 19, 2020; Peer review completed: July 19, 2020; Revised version received and accepted: July 20, 2020; Published: July 23, 2020.

DOI: 10.15376/biores.15.3.7009-7017 